\title{
Energy Storage System optimization for an Autonomous SailBoat
}

\author{
Enrico Boni, Marco Montagni, Andrea Moreschi \\ Department of Information Engineering \\ University of Florence \\ Florence, Italy
}

\author{
Luca Pugi \\ Department of Industrial Engineering \\ University of Florence \\ Florence, Italy
}

\begin{abstract}
Available energy optimization on permanently non -grid-connected systems is a critical task. In fact, optimizing the power consumption of the active sub-systems is only a part of getting an increased autonomy. A full optimization cannot be done without taking into consideration the energy source and the energy storage system, whose efficiency directly effect the total system autonomy. In this paper we present the optimization of the energy storage system for an autonomous sail drone, based on the use of solar panels connected to backup batteries. The proposed study represents a significant use case, not only for the importance and the impact of the proposed sail-drone but also for the involved field application (autonomous self-propelled selfsustained system) which is finding an increasing number of different application and a strong interest among the scientific community.
\end{abstract}

Keywords-Mechatronics, Solar Energy, Maximum Power Point Tracker, Autonomous Vehicle, Battery Management Systems, Energy Storage

\section{INTRODUCTION}

Optimal Energy Management is a fundamental topic for autonomous systems designed to operate for a prolonged time.

In previous research activities authors have developed an autonomous sail drone [1][2]. As a part of the V.E.L.A. (Veicolo Eolico Leggero Autonomo) project financed by Fondazione Cassa di Risparmio di Firenze, authors have introduced significant improvement respect to the original prototype. In particular, in this work it's discussed the optimization of the energy storage and energy management systems which cover a fundamental role in the design of this kind of vehicles [3]. A picture of the UNIFI sailboat is visible in fig. 1 .

Autonomous sailboats [4] represent an emerging technology aiming to solve the problem of designing autonomous marine vehicles able to perform long patrolling mission on sea surface, the so called ASV (autonomous surface vehicles). A brief list of existing vehicle prototype including some specific features (as example catamarans or single hull boats) is visible in fig. 2 .

Since most of the energy involved for the propulsion of sail vehicles is from the wind, this kind of vehicles are designed to be environmentally sustainable, so the remaining energy needs to feed on board systems where the actuation of sailing and

\footnotetext{
This work was supported by Fondazione Cassa di Risparmio di Firenze
} under the V.E.L.A. (Veicolo Eolico Leggero Autonomo) project grant navigation surfaces is usually provided by accumulators fed by solar panels [5]. Such systems typically include the control unit, the communication system, the electric actuation of multiple mechanical devices like the rudder and the boom.

Since solar power is clearly depending from weather conditions and geographic location, the system must be particularly robust in order to assure enough resilience with respect to all these parameters.

Another important aspect regarding the proposed application that clearly influence the design of the energy storage system is represented by sustainability and environmental impact: these vehicles are typically proposed for monitoring environmentally sensitive areas in order to investigate quality of water [6] or to monitor relevant biometric parameters, pollution and so on [7][8][9].

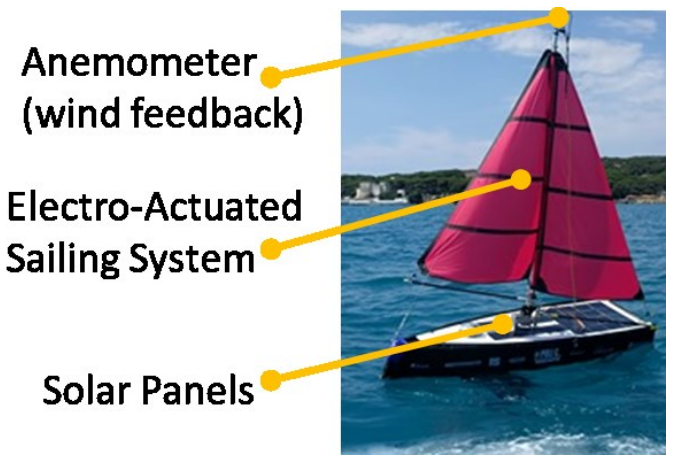

Fig. 1. Unifi Sail Drone, main parts

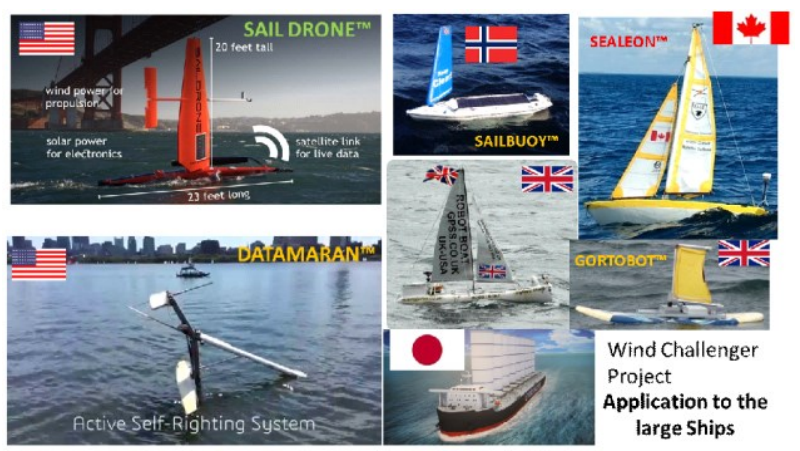

Fig. 2. Examples of Autonomous Sail Boats, Existing Protypes and Projects in advanced development phase. 
Typical applications are also related to the monitoring of marine areas conserving relevant cultural heritages such as underwater archaeological sites [10][11]. All the above described activities are often performed also by underwater vehicles, but recent studies have also often focused their attention on the coordination between surface and underwater vehicles [12][13], especially to better perform the localization of swarms. Also, interaction with flying drones should be expected.

Autonomous sail vehicles can be considered environmentally friendly since null or limited emissions are associated to vehicle functionality (no acoustic emission, no chemical emission, negligible Electro-Magnetic Emission).

However, looking at vehicle sustainability and equivalent environmental impact, also the eventuality of a shipwreck has to be considered.

In this case, on board energy storage represent the most important source of pollution for the environment.

In the original UNIFI prototype, as in many existing prototypes, storage is performed with conventional lead batteries, since weight in a marine application is not much important. Also, sometimes, weight of batteries can be exploited to improve the static distribution of masses in the hull. However, lead batteries represent an unacceptable source of pollution in case of shipwreck.

For this reason, authors have investigated different environmental impact of different battery technologies in terms of Life Cycle assessment.

As visible in fig. 3 which is referred to a specific study performed for the development of a new generation of sustainable electric vehicles is clearly noticeable that modern lithium batteries are clearly superior respect to other conventional solutions also in terms of sustainability [15].

For these reasons, in the new version of the vehicle, authors have focused their attention on lithium batteries removing the older lead-acid ones. In particular, $\mathrm{LiFePO}_{4}$ technology was chosen for its absolute reliability in terms of thermal and chemical stability. This is a feature confirmed by previous experience in the automotive sector [16][17] which is fundamental to assure the required reliability respect to variable and probably hard environmental conditions.

The paper is organized as follows:

- In Sec. II, first are introduced the new solar panel design and the battery pack upgrade, then the solutions to maximize the charging efficiency are described, along with the methods used to validate the new circuits.

- In Sec. III are presented the results of the measurements and tests of the new circuits. The total gain in terms of available energy is then evaluated.

- $\quad$ Sec. IV concludes the paper.

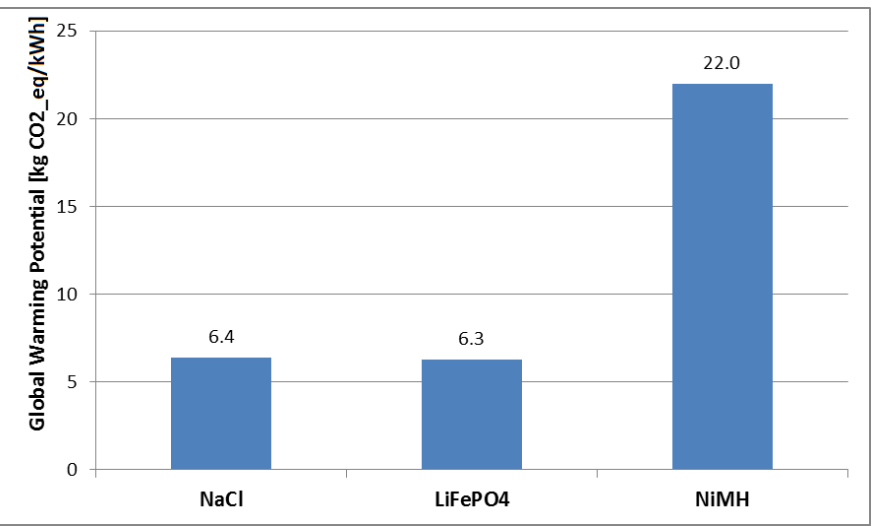

Fig. 3. Comparison in terms of Global Warning Potential for different energy storage technologies [15]

\section{METHODS}

\section{A. New solar panel design}

The original solar panel (fig. 4a) was positioned almost on the rear of the boat and divided into two part. Standard solar cells where employed, and the total installed power was $48 \mathrm{~W}$ nominal (24W each).

The new solar panel design (fig. 4b) includes the use of high-efficiency next-generation SunPower flexible solar cells. Three solar panels are placed on the top-surface of the boat. Two panels are installed on the rear side, one on the left side, the other on the right side. The third panel is on the front side. Each panel has a nominal power of $33 \mathrm{~W}$, they are composed of a series of 20 half cells, each one providing $0.55 \mathrm{~V}$ and $3 \mathrm{~A}$ at maximum power point. The nominal panel voltage is $11 \mathrm{~V}$. Dividing the solar panel in 3 regions allows to maximize the available solar energy, thanks to the fact that at least one full panel is guaranteed being not covered by the sail shadow in all conditions.
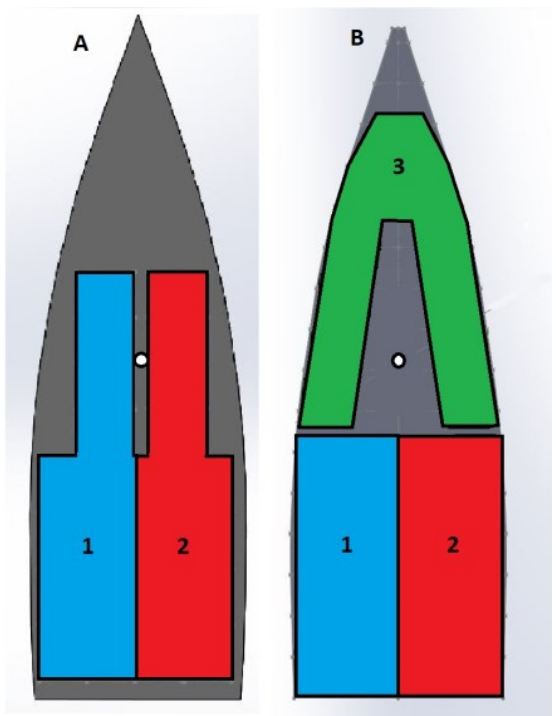

Fig. 4. A: Solar panels position on the first prototype. B: solar panels position on the new prototype 


\section{B. $\mathrm{LiFePO}_{4}$ battery pack}

The original dual battery pack was composed by two LeadGel $12 \mathrm{~V}$ batteries, with a capacity of $12 \mathrm{Ah}$ each.

The new dual battery pack is composed by two independent series of $4 \mathrm{LiFePO}_{4}$ cells, each one with a capacity of $20 \mathrm{Ah}$. The nominal voltage of the battery pack is $13.2 \mathrm{~V}$, with a minimum of $10 \mathrm{~V}(2.5 \mathrm{~V}$ per cell $)$ and a maximum of $14.4 \mathrm{~V}$ (3.6V per cell). The minimum and maximum working voltage of the cells was chosen within the extreme values allowable for this chemistry $(2.45 \mathrm{~V}$ to $3.65 \mathrm{~V})$ to preserve the battery life.

Since the cells in a series can slowly reach different charging states, due to microscopical differences from cell to cell, to avoid damaging the battery we designed a battery balancing circuit. The circuit is based on the BQ76920 chip from Texas Instruments. The chip automatically measures cell voltages and when one reaches the maximum programmed value $(3.6 \mathrm{~V})$ a discharging circuit, in parallel with the cell, is activated. A digital interface allows an external microcontroller to monitor cells status and manually override the protection algorithm. Moreover, the microcontroller can communicate with the central unit of the autonomous sailboat, thus providing vital information related to the battery pack to the main controller.

The two battery strings are OR-ed with two Schottky diodes. This ensure additional power supply reliability regarding the possible failure of one half of the battery pack.

\section{High efficiency MPPT battery charger}

Each panel is equipped with a separate MMPT battery charger, to better cover different shading conditions and to increase the overall reliability of the system. Panels \#1 and \#3 are used to recharge one half of the battery pack, while panel \#2 is connected to the second half of the battery pack.

The old MPPT charger was based on a simple constant panel-voltage circuit. While the circuit is very simple, it actually doesn't fit the use case. In fact, different shading conditions, due to the sail position and boat orientation, easily bring different (lower) MPP voltages for the panel. Moreover, the high temperatures that the panels can reach during a sunny day forced the use of a low MPP voltage, thus lowering the maximal power extraction in all other conditions.

The new MPPT charger is based on the LT8490 chip from Linear Technologies. The chip is a buck-boost switching regulator battery charger. The internal logic provides automatic continuous maximum power point tracking with a perturb-andobserve algorithm. The panel is also scanned periodically to avoid settling on a local maximum power point for long periods of time, in the case of non-uniform panel illumination.

The circuit design involved careful optimization of all the components in order to achieve the maximum efficiency.

Panel input specifications, based on the new solar panels, were: $7 \mathrm{~V}$ to $11 \mathrm{~V}$ input voltage and $3.5 \mathrm{~A}$ maximum input current.

Battery output was configured as $9 \mathrm{~V}$ to $14.8 \mathrm{~V}, 4.3 \mathrm{~A}$ maximum output current.

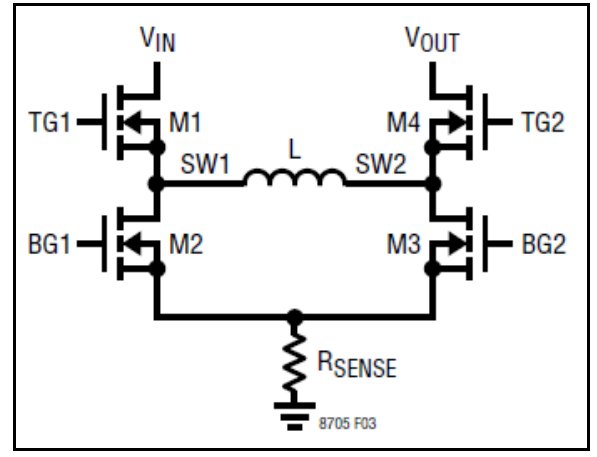

Fig. 5. Buck-boost switching cell topology

Based on the input/output specifications, the buck-boost switching cell (fig. 5) was optimized.

We started choosing a $170 \mathrm{kHz}$ switching frequency: a compromise between reducing the switching losses and keeping the inductor small.

Then, an inductor was selected, considering the lower bound of $7 \mu \mathrm{H}$ due to the combination of switching frequency, $\mathrm{min} / \mathrm{max}$ input/output voltage and current values:

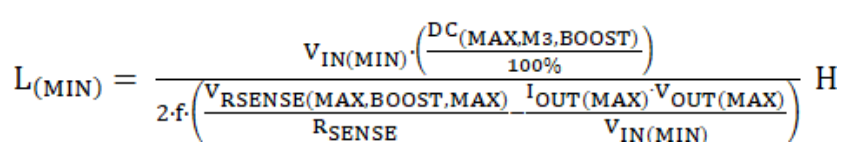

The selected component (Wurth Electronics 74436411500) has $15 \mu \mathrm{H}$ inductance (to keep some margin with the minimum requested inductance) and a DC resistance of $1.3 \mathrm{~m} \Omega$. We evaluated the maximum power dissipation due to resistive losses to be $0.13 \mathrm{~W}$.

The four MOSFETs contribute to power losses by both resistive losses due to channel resistance and switching losses due to input/output capacitance.

Considering all the loss contributions, a TPWR8503NL from Toshiba was selected, with $1 \mathrm{~m} \Omega \mathrm{R}_{\mathrm{DS}(\mathrm{ON})}$ and very low gate charge and input/output capacitance. The estimated maximum total losses were $1.22 \mathrm{~W}$ for the four MOSFETs.

A PCB was designed ad assembled following all the above specifications.

To evaluate the circuit efficiency, the MPPT system was supplied with a current limited power supply, and the output was connected to a constant voltage load. The power supply was swept between $7 \mathrm{~V}$ and $11 \mathrm{~V}$ and for each voltage the current limit was swept between $0.2 \mathrm{~A}$ and $4 \mathrm{~A}$. The output voltage was set to $13.2 \mathrm{~V}$. Input and output voltages, input and output currents were measured with four Peaktech 3440 multimeters connected to a data collecting PC (fig. 6). The corresponding input and output power and thus efficiency was calculated for each setpoint. 


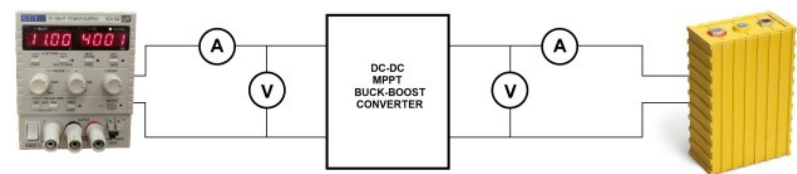

Fig. 6. Measurement setup to evaluate circuit efficiency

\section{RESULTS}

The maximum input power of the designed MPPT charger is $38.5 \mathrm{~W}(11 \mathrm{~V}, 3.5 \mathrm{~A})$, while the maximum estimated switching losses are $1.35 \mathrm{~W}(0.13 \mathrm{~W}+1.22 \mathrm{~W})$. The predicted maximum efficiency is thus $96.5 \%$.

1160 efficiency measurement points where extracted with the measurement setup described in sec. II.

Fig. 7 shows the actual efficiency measurements results. From the graphs we found that the circuit reach the maximum efficiency of $96.2 \%$ at input values of $10.2 \mathrm{~V}, 3.5 \mathrm{~A}$. This well matches with the predicted values.

Regarding the battery pack, for the old lead-acid cells we estimated an $82 \%$ charging/discharging efficiency (total energy extracted from the pack vs total energy provided to the pack), while for the new $\mathrm{LiFePO}_{4}$ pack we estimate a $98 \%$ charge/discharge efficiency. Round-trip efficiency has been chosen as figure of merit since it better describes the total energy available to the system starting from the same initial gross energy availability.

Table I reports the incremental reduction with respect to the nominal panel power (considered at $1000 \mathrm{~W} / \mathrm{m}^{2}$ of irradiance, AM1.5, $20{ }^{\circ} \mathrm{C}$ to $60{ }^{\circ} \mathrm{C}$ ) due to three main reduction factors: sun incidence angle (and average shading), MPPT circuit efficiency, battery charge/discharge efficiency. The last column shows how much energy can realistically be stored and provided to the load in a sunny day considering those factors. As we can see the new system allows to provide $378 \mathrm{Wh}$, while the old one just 105Wh.

The battery balancing chip included in the battery packs has a negligible impact on the overall system efficiency, being its current consumption, when fully active, less than $200 \mathrm{uA}$.

TABLE I. OVERALL EVALUATION OF THE OLD AND NEW ENERGY STORAGE SYSTEM

\begin{tabular}{|l|c|c|l|c|c|}
\hline & $\begin{array}{c}\text { Danel } \\
\text { power }\end{array}$ & $\begin{array}{c}\text { Derated } \\
\text { panel power } \\
\text { due to } 30^{\circ} \\
\text { inclination }\end{array}$ & $\begin{array}{l}\text { Derating } \\
\text { by MPPT } \\
\text { efficiency }\end{array}$ & $\begin{array}{c}\text { Derating by } \\
\text { battery } \\
\text { chemistry } \\
\text { charging } \\
\text { efficiency }\end{array}$ & $\begin{array}{c}\text { Energy } \\
\text { available } \\
\text { with } 6 \text { h } \\
\text { of full } \\
\text { sun }\end{array}$ \\
\hline $\begin{array}{l}\text { Old } \\
\text { design }\end{array}$ & $48 \mathrm{~W}$ & $32 \mathrm{~W}$ & $\begin{array}{l}21 \mathrm{~W} \\
(67 \%)\end{array}$ & $\begin{array}{c}17.5 \mathrm{~W} \\
(\mathrm{~Pb}, 82 \%)\end{array}$ & $105 \mathrm{Wh}$ \\
\hline $\begin{array}{l}\text { New } \\
\text { design }\end{array}$ & $99 \mathrm{~W}$ & $66 \mathrm{~W}$ & $\begin{array}{l}64 \mathrm{~W} \\
(96.2 \%)\end{array}$ & $\begin{array}{c}63 \mathrm{~W} \\
\left(\mathrm{LiFeP}_{4},\right. \\
98 \%)\end{array}$ & $378 \mathrm{Wh}$ \\
\hline
\end{tabular}
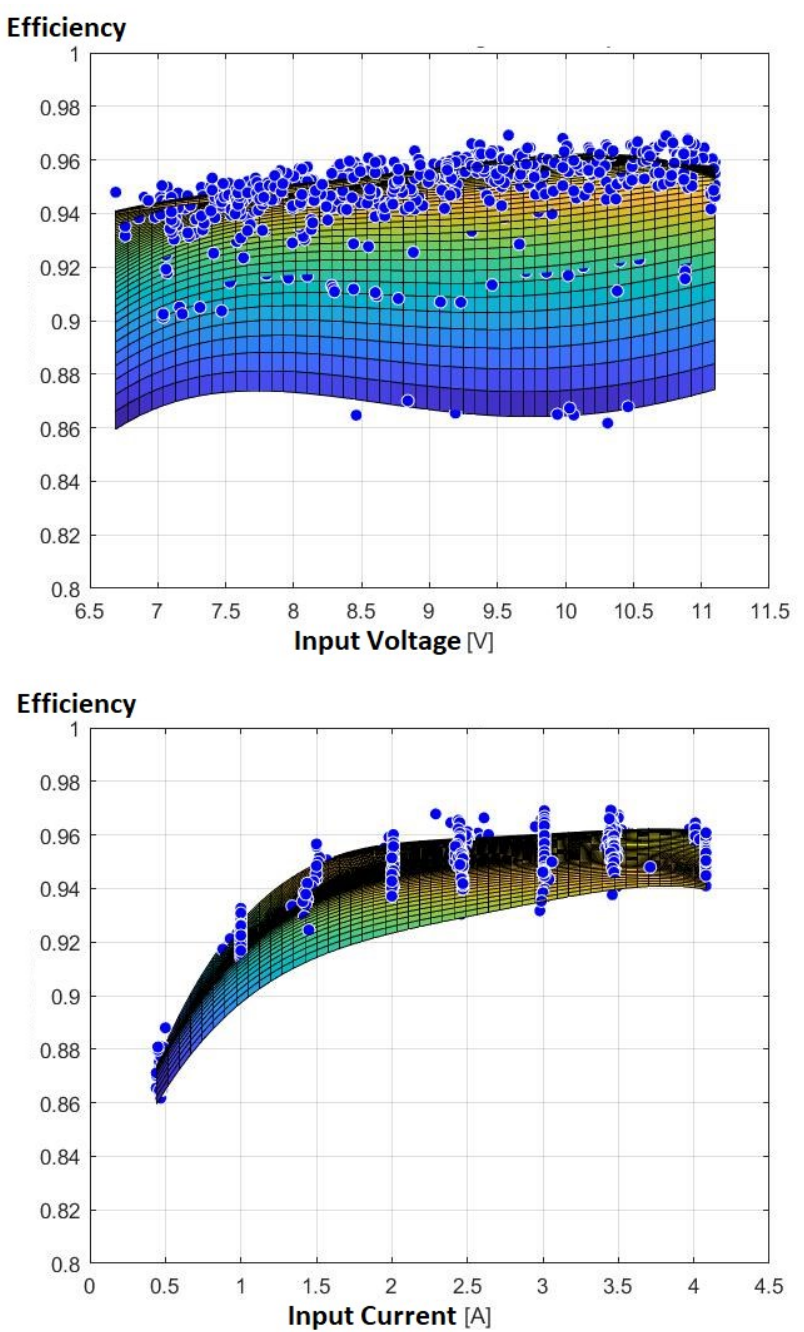

Fig. 7. Measurement results, plotted against input voltage (Top) and Input Current (bottom). The shaded surface is the least square interpolant over the measured points (blue dots)

\section{CONCLUSION}

Thanks to the new design, the energy stored and retrievable in a given amount of time has been increased by a factor of 3.6. Considering that UNIFI sailboat draws a total of $4 \mathrm{~W}$ electrical power on average $(1.5 \mathrm{~W}$ are due to the central unit, the IMU, the GPS system and the IRIDIUM communication system. $2.5 \mathrm{~W}$ are due to the electric actuation of rudder and boom), it is now possible to store enough energy to run the drone for 4 days with a single sunny day (6h). Moreover, the old battery pack had a total energy storage capacity of $288 \mathrm{Wh}$, while the new one has $480 \mathrm{Wh}$. In this way the proposed system can be considered completely satisfying in terms of resilience with respect to harsh weather conditions and component performance degradation as, in particular, the aging of batteries and the solar panel performance loss (due to salt deposits or other pollution sources). Current work will be completed by 
verification and validation activities that should be performed during vehicle commissioning.

\section{ACKNOWLEDGMENT}

Authors wish to thank all the sponsors and the students that have sustained the development and a testing of the UNIFI sail Drone in the last two years.

In particular, authors wish to thank the student Andrea Bertini from university of Florence for the support that has provided to experimental activities performed on various marine locations.

\section{REFERENCES}

[1] L. Pugi, B. Allotta, E. Boni, F. Guidi, M. Montagni, T. Massai, Integrated Design and Testing of an Anemometer for Autonomous Sail Drones (2018) Journal of Dynamic Systems, Measurement and Control, Transactions of the ASME, 140 (5), art. no. 055001. DOI:10.1115/1.4037840

[2] B. Allotta, L. Pugi, T. Massai, E. Boni, F. Guidi, M. Montagni, Design and calibration of an innovative ultrasonic, arduino based anemometer (2017) Conference Proceedings - 2017 17th IEEE International Conference on Environment and Electrical Engineering and 2017 1st IEEE Industrial and Commercial Power Systems Europe, EEEIC / I and CPS Europe 2017, art. no. 7977450. DOI: 10.1109/EEEIC.2017.7977450

[3] Z. Zhang, Z. Yao, Q. Sun, H. Qian, Energy Optimization of Automatic Hybrid Sailboat (2019) 2018 IEEE International Conference on Robotics and Biomimetics, ROBIO 2018, art. no. 8664880, pp. 480-485. DOI: 10.1109/ROBIO.2018.8664880

[4] J. Abril, J. Salom, O. Calvo, Fuzzy control of a sailboat (1997) International Journal of Approximate Reasoning, 16 (3-4 SPEC. ISS.), pp. 359-375.

[5] P.F. Rynne, K.D. Von Ellenrieder, Development and preliminary experimental validation of a wind- and solar-powered autonomous surface vehicle (2010) IEEE Journal of Oceanic Engineering, 35 (4), art. no. 5634056, pp. 971-983. DOI: 10.1109/JOE.2010.2078311

[6] A.G. Da Silva Junior, S.T. De Lima Sa, D.H. Dos Santos, Á.P.F. De Negreiros, J.M.V.B. De Souza Silva, J.E. Álvarez Jácobo, L.M. Garcia Gonçalves, Towards a real-time embedded system for water monitoring installed in a robotic sailboat (2016) Sensors (Switzerland), 16 (8), art. no. 1226 , . DOI: $10.3390 / \mathrm{s} 16081226$

[7] A. Tengberg, M. Nakata, D. Roach, Hydrography and environmental measurements from mobile platforms (2018) 2018 OCEANS MTS/IEEE Kobe Techno-Oceans, OCEANS - Kobe 2018 DOI: 10.1109/OCEANSKOBE.2018.8559097

[8] S.S. Rathour, N. Kato, H. Senga, T. Tanabe, M. Yoshie, T. Tanaka, Development of a robotic floating buoy for autonomously tracking oil slicks drifting on the sea surface (SOTAB-II): Experimental results (2016) Applications to Marine Disaster Prevention: Spilled Oil and Gas Tracking Buoy System, pp. 95-127. DOI: 10.1007/978-4-431-55991-7_4
[9] A. Tonacci, G. Lacava, M.A. Lippa, L. Lupi, G. Pioggia, L. Gualdesi, C. Domenici, M. Cocco, A smart multimodal innovative model for marine environmental monitoring (2015) Proceedings - 29th European Conference on Modelling and Simulation, ECMS 2015, pp. 455-461.

[10] B. Allotta, S. Baines, F. Bartolini, F. Bellavia, C. Colombo, R. Conti, R. Costanzi, C. Dede, M. Fanfani, J. Gelli, H.T. Gundogdu, N. Monni, D. Moroni, M. Natalini, M.A. Pascali, F. Pazzaglia, L. Pugi, A. Ridolfi, M. Reggiannini, D. Roig, O. Salvetti, E.I. Tekdemir, Design of a modular Autonomous Underwater Vehicle for archaeological investigations(2015) MTS/IEEE OCEANS 2015 - Genova: Discovering Sustainable Ocean Energy for a New World, art. no. 7271398, .DOI: 10.1109/OCEANS-Genova.2015.7271398

[11] B. Allotta, L. Pugi, F. Bartolini, R. Costanzi, A. Ridolfi, N. Monni, J. Gelli, G. Vettori, L. Gualdesi, M. Natalini, The thesaurus project, a long range AUV for extended exploration, surveillance and monitoring of archaeological sites (2013) Computational Methods in Marine Engineering V - Proceedings of the 5th International Conference on Computational Methods in Marine Engineering, MARINE 2013, pp.

[12] B. Allotta, R. Costanzi, E. Meli, L. Pugi, A. Ridolfi, G. Vettori, Cooperative localization of a team of AUVs by a tetrahedral configuration (2014) Robotics and Autonomous Systems, 62 (8), pp. 1228-1237. DOI: 10.1016/j.robot.2014.03.004

[13] B. Allotta, L. Pugi, R. Costanzi, G. Vettori, Localization algorithm for a fleet of three AUVs by INS, DVL and range measurements (2011) IEEE 15th International Conference on Advanced Robotics: New Boundaries for Robotics, ICAR 2011, art. no. 6088608, pp. 631-636. DOI: 10.1109/ICAR.2011.608860

[14] S. Kvaterniuk, V. Petruk, O. Kochan, V. Frolov, Multispectral ecological control of parameters of water environments using a quadrocopter (2020) Studies in Systems, Decision and Control, 198, pp. 75-89. DOI: 10.1007/978-3-030-11274-5_6

[15] L. Berzi, E. Bobi, F. Grasso, F. Del Pero, M. Delogu, R. Savi, Electrification of Directional Drilling Machines for Sustainable Trenchless Excavations , Proceedings - 2019 IEEE International Conference on Environment and Electrical Engineering and 2019 IEEE Industrial and Commercial Power Systems Europe, EEEIC/I and CPS Europe 2019 Genova 11-14 June 2019

[16] E. Locorotondo, L. Pugi, L. Berzi, M. Pierini, G. Lutzemberger, Online Identification of Thevenin Equivalent Circuit Model Parameters and Estimation State of Charge of Lithium-Ion Batteries (2018) Proceedings - 2018 IEEE International Conference on Environment and Electrical Engineering and 2018 IEEE Industrial and Commercial Power Systems Europe, EEEIC/I and CPS Europe 2018, art. no. 8493924, . DOI: 10.1109/EEEIC.2018.8493924

[17] E. Locorotondo, L. Pugi, L. Berzi, M. Pierini, A. Pretto, Online State of Health Estimation of Lithium-Ion Batteries Based on Improved AmpereCount Method (2018) Proceedings - 2018 IEEE International Conference on Environment and Electrical Engineering and 2018 IEEE Industrial and Commercial Power Systems Europe, EEEIC/I and CPS Europe 2018, art. no. 8493825, .DOI: 10.1109/EEEIC.2018.8493825 